\title{
Exposure to Video Display Terminals and Associated Neuromuscular Pain and Discomfort in Male and Female Undergraduate University Students
}

\author{
ALTAF GHORI, DR. WALLY BARTFAY, DR. EMMA BARTFAY \\ AND DR. OTTO SANCHEZ, University of Ontario Institute of Technology
}

\begin{abstract}
This paper explores the gender differences with respect to potential negative physical effects associated with prolonged Video Display Terminal (VDT) use. In this cross-sectional survey, we distributed selfreported health questionnaire along with the Nordic Musculoskeletal Questionnaire (NMQ) to 278 University of Ontario students (95 males and 183 females, aged between 17-32 years) in Oshawa, Ontario, Canada. Results showed that female students suffered more pain/discomfort in the neck/shoulder/hand and wrist $(64.1 \%)$ in comparison to males (45.7\%). Location of pain was also different in female students when compared to male students. This study provides preliminary evidence to suggest that female UOIT students experienced increased negative health effects on exposure to VDTs in comparison to male students. This study will help facilitate more targeted interventions towards millennials and assist them in reducing pain/discomfort they may experience when using devices with VDTs.
\end{abstract}

Keywords: VDTs, VDT use and health, VDTs and physical health, VDT and repetitive strain, VDT and carpal tunnel-like symptoms 


\section{Introduction}

A video display terminal (VDT) is defined as a device, either in the form of Cathode Ray Tube (CRT), Liquid Crystal Display (LCD) or any other form of image projection technology that converts electrical signals into visual display. These video displays can be used for the purposes of relaying information in the form of images, photos, texts, and/or films. Examples of VDTs include computers, laptops, electronic notebooks, tablets, and a variety of portable cellular phones and devices (e.g., BlackBerrys, iPhones, smartphones) (Young, 1990; Raynes, 2001). The use of electronic and digital devices and technologies with VDTs has increased exponentially in the past few decades in many countries around the world (Internet World Stats, 2014). In Canada and other industrialized nations in the world (e.g., UK, EU, USA, Australia) accessing the Internet via VDT-based devices has become one of the primary means of communication, information sharing, and entertainment (Klussman et al., 2008; Kormas et al., 2011; Travers \& Stanton, 2002). It has been estimated that $45 \%$ of youth and young adults are online every day in North America, and as of July, 2010, Canada had the world's greatest number of Facebook users in proportion to its population; the United Kingdom was second and the USA was third (CEFRIO, 2010; O’Neil et al. 2012).

Statistics Canada (2013) reports that female enrollment in universities has risen steadily to about approximately $60 \%$. Additionally, female enrollment in 2008 was approximately $62 \%$. Currently, there is a dearth of investigations into the relationship between electronic or digitallybased mobile devices and technologies (e.g., cellular phones, tablets, iPods, laptop computers) with VDTs and their potential health effects on Canadian male and female college or universityaged young adults who are high users of these devices and technologies. There are only a handful of studies to date that have reported the differences between males and females with 
respect to the potential negative health effects related to VDT exposure (e.g. Wu et al., 2012;

Rajagopal et al., 2012; Das \& Ghosh, 2010). For example, Wu et al. (2012), who studied Chinese officer workers, reported that the prevalence of work-related musculoskeletal disorders was higher in women $(64.6 \%)$ compared to men (46.7\%). Similarly, Rajagopal et al. (2012) reported a higher prevalence of musculoskeletal pain among female college students (96\%) when compared to their male counterparts (76\%). A study by Das \& Ghosh (2010) of office workers using VDTs reported that females suffer higher rates of repetitive strain injury in general as well as in the workplace. Hence, we sought to conduct the present investigation in response to this noted gap in the empirical literature. That is to say, the investigations involving gender differences with VDT exposure and negative health outcomes conducted to date have focused on office workers, and not young adults who are university students and high-end users of these technologies. This study has the potential to facilitate more targeted interventions towards Canadian millennials who are high-end VDTs and assist them in reducing the pain/discomfort they experience when using various devices. This study can also help support a needs-based access to health interventions assisting people who experience pain as a result of VDT use.

\section{VDT use and negative physical symptoms}

El-Bestar, El-Mitwalli, and Kashaba (2011) reported that approximately $12.6 \%$ of their study participants had symptoms suggestive of median nerve neuropathy. Of the $12.6 \%$ of participants that had these symptoms, approximately $33.3 \%$ were clinically confirmed as having Carpal Tunnel Syndrome (CTS). Prevalence of CTS among VDT users was found to be 3.3\%. Although the mean age in their study was higher $(51.5 \pm 7.2$ years $)$ when compared to other studies, they attributed this difference to the relatively new addition of VDTs in workplaces. This 
study suggests an association between VDT use and the development of CTS-like symptomatology in office workers.

El-Bestar et al. (2011) reported that the prevalence of neck/upper extremity musculoskeletal disorders (MSDs) among VDT users was higher $(\approx 28.3 \%)$ in comparison to non-VDT users $(\approx 14.3 \%)$. Prevalence of cervical spondylosis, cervical disc space narrowing, and cervical radiculopathy was higher among VDT users (18.3, 18.3, and 10\%, respectively), when compared to controls $(11.4,11.4$, and $2.8 \%$ respectively). Similarly, a study by Hakala et al. (2010) examined the effects of ergonomic instruction on computer related symptoms (i.e. headache, neck-shoulder pain, and lower back pain). They found that using the computer for more than one hour daily was associated with negative health symptoms in the upper extremities (i.e., the neck, shoulder, hands, fingers, and wrists). Similarly, Das and Ghosh (2010) suggested that VDT workers who performed hand intensive jobs had a higher rate of pain in the upper extremities of the body. A growing body of evidence suggests that use of mobile devices and technologies with VDTs results in negative physical effects such as muscle pain and discomfort (i.e., neck, shoulder) (Balci \& Aghazadeh, 2003; Hsu \& Wong, 2013; Kormas et al., 2011;).

Pillastrini et al. (2010) examined the relationship between lower back pain and VDT use with a Rapid Entire Body Assessment (REBA) method that uses Action Level (AL) scores as an index for measuring musculoskeletal risk and urgency. They found that there was a reduction in lower back pain when an ergonomic intervention was introduced. Das and Ghosh (2010) suggested that prolonged VDT use is associated with an increase in the incidence of musculoskeletal discomfort primarily in the upper extremities as well as the lower back among male and female VDT users. Their study suggests that the most common complaint among VDT 
workers is lower back pain and neck pain. They noted that this may be associated with prolonged awkward positioning while engaged in VDT work.

Considering the increasing number of musculoskeletal disorders associated with VDT use, the present study aims to examine the relationship between the negative health effects and the use of and/or exposure to mobile electronic or digital devices and technologies with VDTs by male and female undergraduate university students in the Durham Region of Ontario, Canada.

\section{Methods}

\section{Ethics Approval}

Research Ethics Board (REB) approval was granted for this study (Ethics approval number: REB 12-120) by the UOIT Research Ethics Board.

\section{Study Design and Participant Recruitment}

A cross-sectional study was conducted to examine exposure to a variety of mobile electronic and digitally-based technologies and devices that use VDTs (e.g., cellular phones, laptops) and various negative health related conditions and disorders (e.g., neck and shoulder pain, back pain). A non-random, purposive, convenient sampling method was employed, recruiting students at the University of Ontario Institute of Technology (UOIT), a state-of-the-art university wherein faculties rely on modern technology including laptops and computers.

The recruitment of these students was done through oral invites/addresses made in selected classes. The sample consisted of undergraduate students from various divisions such as nursing, kinesiology, medical laboratory science, health sciences, and business and information technology. These clusters were decided based on permission given by the respective professors to conduct the survey in their classes during class time; selection of these divisions is not likely to influenced the results of the study as health science students are not more likely to report 
outcomes than other students (Waterman and Weinman, 2014). An average of approximately 10 minutes of class time was allotted for the distribution and return of a hard copy version of the questionnaires. A total of 278 of $2^{\text {nd }}, 3^{\text {rd }}$ and $4^{\text {th }}$ year university students participated in the study, of which $65.83 \%$ were females aged between $17-32$ years (mean age 22.32 years) and $34.17 \%$ were males aged between 17-32 years (mean age 22.34 years).

\section{Outcome Measure}

A hard copy of a self-reported demographic questionnaire along with the Nordic Musculoskeletal Questionnaire (NMQ) was used to elicit responses from the students between September 2013 to December 2013 (please see Appendix A). The reliability of the NMQ is fair to good (kappa $[k]$ coefficient values ranging from 0.40-0.75). The NMQ questionnaire is reliable as the majority of $k$ values for the symptom variables were above 0.55 (Cook, et al. 2002). Disagreement with the NMQ questionnaire when compared to the clinical history for this instrument has been reported to range from $0-20 \%$ with a validity of $80 \%-100 \%$ (Kuorinka et al, 1987; Crawford, 2007). The outcome measure was self-reported pain in the neck, shoulders, hands, and wrists. These variables were measured using a Visual Analogue Scale (VAS scale). VAS are helpful to measure strength, magnitude, or intensity of the participants' subjective feelings, sensations, or attitudes about specific signs, symptoms, and situations (Burns \& Grove, 2011).

\section{Data Analysis}

SPSSX version 21 (Chicago, IL) was used for descriptive and inferential statistics. Descriptive statistics included mean, standard deviation and ranges presented in table or graphic forms. Inferential statistics used were independent samples student $t$-test, Chi-Squared test, Pearson's correlation as well as post-hoc path analysis. The dependent variables were 
musculoskeletal pain in the neck, shoulder, upper arm, fingers, and back pain. The independent variables included the amount of time spent on the cell phone/computer/social networking sites/Twitter/YouTube/coursework. A p-value of $\leq 0.05$ is deemed to be significant.

Linear regression and path analysis were used to determine the relationship between key variables such as physical pain and discomfort, as well as the total number of hours exposed to VDTs, including time spent on Facebook, Twitter, checking e-mails, YouTube, coursework, Internet browsing (both on cell phones as well as other devices), in front of VDTs playing games, and talking and texting on the cell. Path analysis was used to study patterns of causation. Path analysis is a diagrammatic representation of presumed causal linkages among variables; it relies on multiple regression. The aim of path analysis is to give an estimate of the magnitude and significance of a proposed causal connection between different sets of variables, which is explained by means of a diagram. In path analysis, the relationship between variables is assumed to be linear (Ho, 2014; Polit \& Hungler, 1991; Lenior, Dingemans, Schene \& Linszen, 2005).

\section{Results}

A total of 278 university students participated in the study, of which $65.83 \%$ were females aged between 17-32 years (mean age 22.32 years) and $34.17 \%$ were males aged between 17-32 years (mean 22.34 years); the participants were in their $2^{\text {nd }}, 3^{\text {rd }}$, and $4^{\text {th }}$ years of university. Young male university students spent an average of 750 minutes/day in front of VDTs (750.02 \pm 571.60). Females spent more time on average in front of VDTs compared to their male counterparts $(846.57 \pm 445.27$ minutes/per day). Approximately $45 \%$ of females experienced occasional pain/discomfort in the neck following prolonged exposure to VDTs compared to males $(18 \%)$, while $35.4 \%$ of females reported pain in the shoulders compared to only $13.8 \%$ of males, and $37 \%$ of females reported pain in the upper back, compared to $18.1 \%$ of males who 
experienced pain in the same region. Approximately $33 \%$ of females had pain in the wrist/hands compared to $31.9 \%$ of males after exposure to devices with VDTs. Moreover, $32 \%$ of females reported experiencing pain in the lower back compared to $23.4 \%$ of males who reported pain in the same region. Tables 1 and 2 reported the gender-specific exposure times and gender-specific outcomes of included participants.

Table 1: Average Gender-specific Exposure Times (reported in total minutes/day)

\begin{tabular}{|l|l|l|l|}
\hline Variable (time in minutes) & Males & Females & p-values \\
$($ Mean \pm SD) & $($ Mean \pm SD) & \\
\hline Facebook time & $75.16 \pm 77.40$ & $88.69 \pm 84.67$ & 0.19 \\
\hline Twitter time & $27.79 \pm 74.04$ & $22.62 \pm 56.43$ & 0.52 \\
\hline Time reading e-mails & $37.58 \pm 74.52$ & $40.16 \pm 30.73$ & 0.68 \\
\hline Time playing games & $63.16 \pm 101.73$ & $13.44 \pm 36.08$ & $0.00^{* *}$ \\
\hline Time on YouTube & $75.02 \pm 99.12$ & $62.97 \pm 71.92$ & 0.25 \\
\hline Time on Internet & $145.21 \pm 174.83$ & $121.82 \pm 111.45$ & 0.24 \\
\hline Time on Coursework & $159.89 \pm 147.46$ & $231.34 \pm 137.64$ & $0.00^{* *}$ \\
\hline Talking on cell & $31.60 \pm 41.59$ & $41.21 \pm 48.37$ & $0.10^{*}$ \\
\hline Texting & $103.89 \pm 153.83$ & $186.72 \pm 228.73$ & $0.00^{* *}$ \\
\hline Browsing Internet on cell phone & $35.05 \pm 44.40$ & $43.52 \pm 58.79$ & 0.22 \\
\hline Total minutes spent on technology & $750.02 \pm 571.60$ & $846.57 \pm 445.27$ & 0.12 \\
\hline Note: All values & & & \\
\hline
\end{tabular}

Note: All values shown are shown are $\bar{X} \pm$ S.D. $* *$ indicates $\mathrm{p} \leq 0.01, *$ indicates $\mathrm{p}=0.10$ 
HEALTH TOMORROW, VOL. 3 (2015)

Table 2: Average self-reported health and pain using VAS scale

\begin{tabular}{|l|l|l|l|}
\hline Variables & Males & Females & p-values \\
\hline Physical Health & $7.56 \pm 1.49$ & $7.22 \pm 1.54$ & 0.08 \\
\hline Mental Health & $7.97 \pm 1.60$ & $7.85 \pm 1.69$ & 0.58 \\
\hline $\begin{array}{l}\text { Overall Physical pain } \\
\text { (neck, shoulders, } \\
\text { wrists) }\end{array}$ & $3.69 \pm 2.59$ & $4.40 \pm 2.35$ & $0.02^{*}$ \\
\hline
\end{tabular}

Note: All values shown are shown are $\bar{X} \pm$ S.D. ${ }^{* *}$ indicates $\mathrm{p} \leq 0.01$, * indicates $\mathrm{p}<0.05$.

Physical health and mental health outcomes are defined as any self-reported inability to adapt to physiological stressors such as pain or discomfort other than in the neck, shoulder, hand or wrist. Mental health is the self-reported inability to cope with psychological stressors such as stress and anxiety manifesting as lack of sleep and loneliness among young Canadian adults (Huber et al., 2011). Overall physical pain is the pain/discomfort experienced by the respondents in the neck, shoulders, and wrists. All these variables were measured on a VAS scale.

The Chi-Squared test showed that females suffered more pain/discomfort in the neck, shoulder, hand, and wrist (64.1\%) in comparison to their male counterparts $(45.7 \%)\left[\chi^{2}(2, \mathrm{~N}=\right.$ $275)=18.463, \mathrm{p}<0.01]$. Pearson's correlation indicated a moderate positive relationship between the total number of hours spent in front of a VDT and online coursework ( $\mathrm{r}=.53$, $\mathrm{p}<0.01)$ and a significant but weak positive correlation between playing games online and total number of hours spent in front of a VDT $(r=.20, p \leq 0.01)$. In female students, online coursework had a moderately significant positive correlation on total number of minutes spent in front of a $\operatorname{VDT}(\mathrm{r}=.53, \mathrm{p} \leq 0.01)$ 


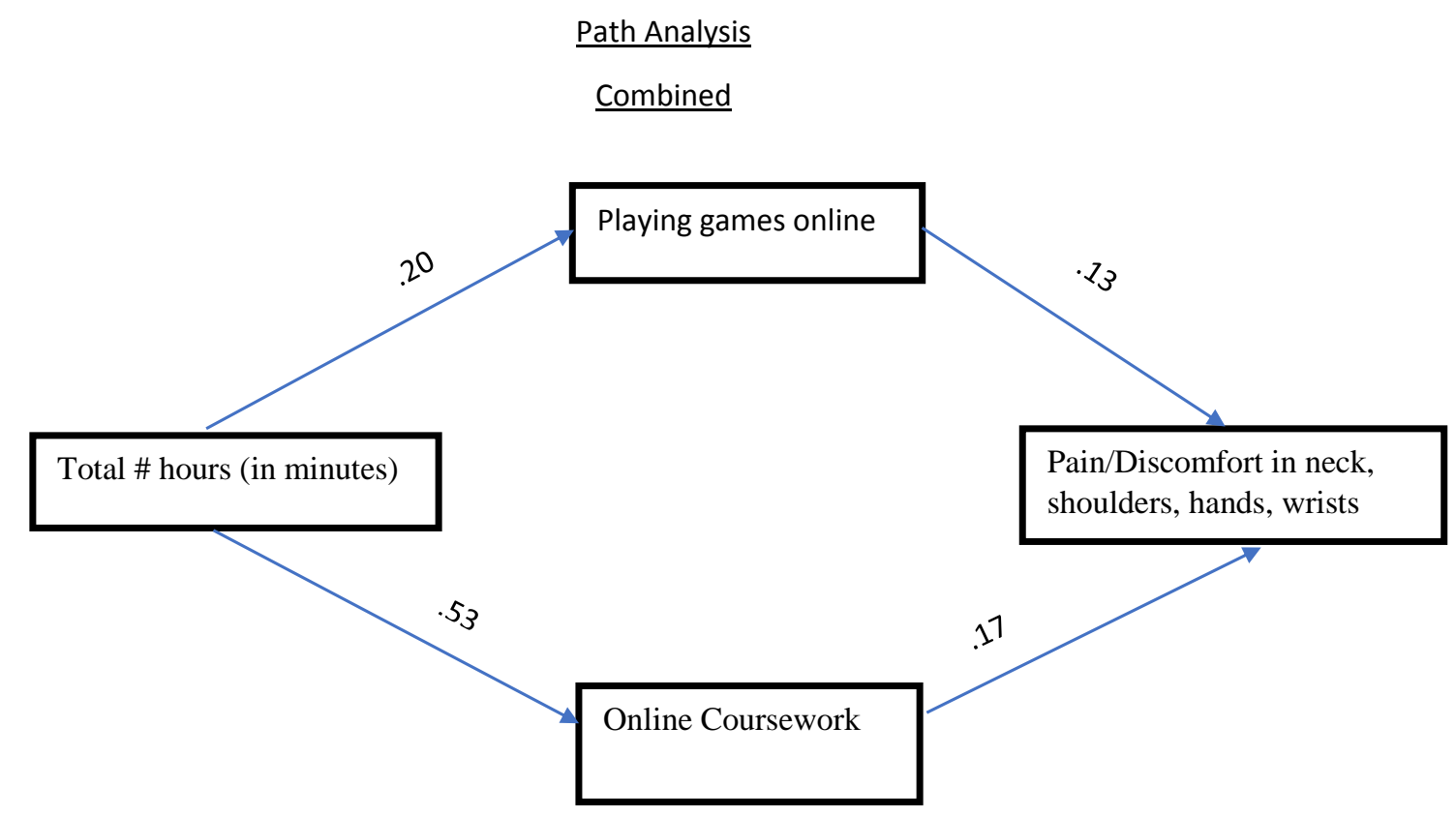

Fig 1: Path analysis showing the direct and indirect effects of VDT exposure

Path Analysis (see Figure 1, above) revealed that there was an indirect effect of exposure to VDTs (measured by total number of minutes in front of a VDT) and pain/discomfort in the neck, shoulder, hand and wrist via coursework (.09) (obtained by multiplying the standardized regression coefficient $(\beta=.53)$ and $(\beta=.17)$. Similarly, an indirect effect was observed on pain/discomfort in the neck, shoulders, hands and wrists from online gaming (.03). The total indirect effect of exposure to VDT (measured as the total number of minutes in front of a VDT) 
was .12.

Path Analysis

Females

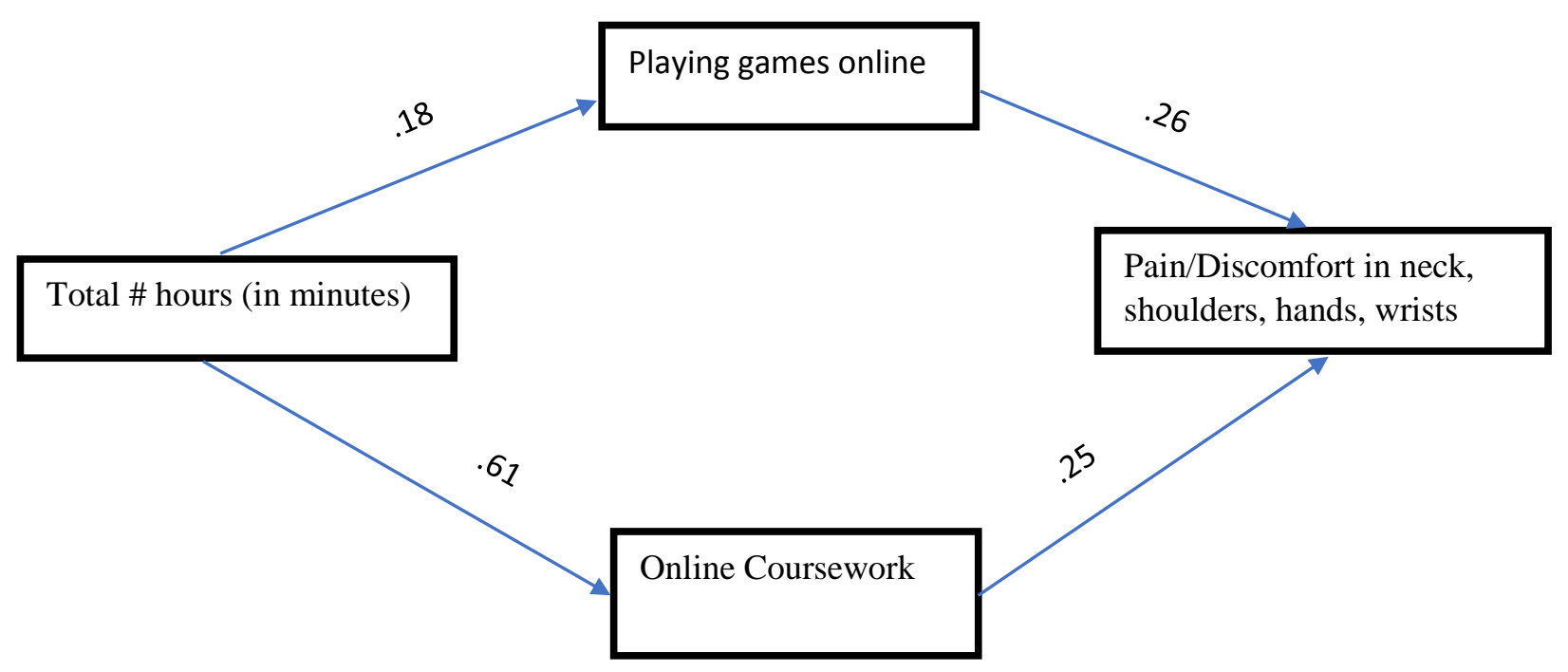

Fig. 2: Path analysis showing direct and indirect relationship to VDT exposure among female students

Among female university students (see Figure 2, above), VDT exposure had an indirect effect on pain/discomfort in the neck, shoulders, hands, and wrists through two different routes. The first is via playing games online; the indirect effect amounts to be .05 (obtained by multiplying the standard regression coefficients $(\beta=.18)$ and $(\beta=.26)$. Secondly, the indirect effect that VDT exposure has on pain/discomfort (neck, shoulders, hands, wrists) via coursework was found to be .15 . There was no such direct or indirect effect of exposure to VDTs on pain/discomfort (neck, shoulders, hands and wrists) among their male counterparts.

\section{Discussion and Recommendations}

The goal of this cross-sectional study was to examine the differences in pain reported by male and female UOIT students who are high-end users of VDTs. In this study, undergraduate 
students of UOIT who were high-end users of VDTs reported suffering from increased pain and discomfort in the neck, shoulder, hand, and wrists. There is a growing body of evidence to suggest that prolonged exposure to VDTs may result in pain in different regions of the body (Balci \& Aghazadeh, 2003; Hsu \& Wang, 2013; Kormas et al., 2011). Our study found that prolonged VDT exposure is positively associated with hand/wrist symptomatology in both males and females. This finding is in agreement with El-Bestar et al. (2010), who found an increased prevalence of carpal tunnel-like symptoms among VDT workers. Their sample consisted, however, of older populations (mean age 51.5 \pm 7.2 )

Our findings suggest that there is high prevalence of neck (45\%) and shoulder discomfort (35\%) associated with VDTs in millennials. This finding is consistent with a study by Hsu and Wong (2003) who examined data-entry personnel, programing engineers, CAD engineers, and fabrication engineers. The researchers reported an increased prevalence of upper extremity discomfort of about $42 \%$ (including neck, shoulder, upper arm, forearm/elbow, wrist, and fingers). This finding is also in agreement with El-Bestar et al. (2010) who studied telecommunication employees. El-Bestar et al. (2010) reported a positive association between prolonged exposure to VDTs and musculoskeletal discomfort particularly in the upper extremities and neck among VDT. Similarly, Hakala et al. (2010) found that using the computer for more than one hour/day was associated with negative health symptoms in the upper extremities including the neck, shoulder, hands, fingers and wrists in 12-18 year old young adolescents. Loghmani et al. (2013) noted that approximately $89 \%$ of office workers reported musculoskeletal symptomatology within a period of 1 year. The researchers found that most of the musculoskeletal symptoms were reported in the neck region (69.2\%), lower back (58.2\%), knees $(41.8 \%)$, and shoulders $(35.2 \%)$. 
Smith, Louw, Crous, and Grimmer-Sommers (2009) reported that neck pain reported by males and females were similar (20.1\% and $19.6 \%$, respectively). By contrast, our findings suggest that female students suffer greater amounts of pain/discomfort in the neck in comparison to male students. Our finding may be partially explained by the fact that female students reported increased VDT screen time exposure in comparison to their male counterparts. This finding is consistent with the findings of Das \& Ghosh (2010), who reported that female VDT workers suffered more discomfort compared to their male counterparts. Similarly, Johnston et al. (2010) reported that workers who spent $>2$ hours at a time on the computer experienced greater neck pain and disability. However, their study involved female office workers exclusively. Additionally, similar findings were reported by Wu et al. (2012) who examined the prevalence of self-reported Work-related Musculoskeletal Disorders (WMSDs) for office workers who are exposed to VDTs. They noted that the prevalence of Work-related Musculoskeletal Disorders of the neck (WMSD-N) was substantially higher in women (64.6\%) when compared to men (46.7\%). Berkley (1997) found that women tend to report more pains in multiple body regions more often than men. There are differences in the way pain mechanisms operate among men and women, particularly in the way pain is learned and stimuli are interpreted. Bartley \& Fillingham (2013) argue that men and women respond to pain differently with respect to risk of pain and increased pain sensitivity. Both risk of pain and increased pain sensitivity are more prevalent in women. Taken together, these findings suggest that females experience increased pain and discomfort in various regions of the body as a result of prolonged VDTs, in comparison to males. What may explain the increase in reporting of pain and discomfort among female students exposed to VDTs when compared to their male counterparts may be the fact that females tend to report ill health/negative health outcomes more often than males (Wang et al., 2013; Gerritsen \& 
Deville, 2009). Future investigations may include hormonal, psychological, and social factors that may contribute to differences in pain perception among males and females. Additionally, future pharmacokinetic, pharmacodynamics, and behavioural studies can be of benefit in pain management and gender-specialized care (Greenspan et al., 2007; Darnall \& Suarez, 2009).

Our findings suggest that university students spent the majority of their online time browsing the Internet and/or visiting social media sites such as Facebook. Specifically, both males and females in our study reported spending most of their time online doing coursework and browsing the Internet. Online coursework was found to be a significant predictor of pain in the neck, shoulder, hands, and wrists in females only. This could be related to the fact that females spent more time doing coursework in comparison to their male counterparts (see table 1). This finding is consistent with that of Odell et al. (2000) who reported that although Internet usage is almost similar among male and female college students, female students spent most of their time online doing course work while their male counterparts played online games, copied and listened to music.

\section{Conclusions}

This study was conducted because there are not many studies in the empirical literature that examine the negative health effects of VDT use among university students from a specifically Canadian perspective. The few that examine these outcomes concentrate on specific devices such as mobile hand held devices. Our study takes into account all types of VDT devices such as laptops, cellular phones, smartphones, and tablets. Prolonged exposure to VDTs may predispose university students in general to a host of negative health effects including neck, shoulder, hand, and wrist pain or discomfort. Particularly, our study reported increased pain/discomfort among female university students when compared to their male counterparts. 
There is very little literature comparing Canadian male and female university students and the negative effects of exposure to VDTs. To our knowledge, this is only the second Canadian study to examine the negative health effects of VDT exposure on university students. Our study is the first to examine gender differences in VDT use among Canadian university students. Several studies have suggested that females tend to report ill health/negative health outcomes more often than males (Wang et al., 2013; Gerritsen \& Deville, (2009). We recognize that gender stereotyping may be a limitation of this study; however, there are several studies that suggest sex differences in pain sensitivity. Additionally, men elicited increased pain tolerance when compared to women (Alabas, Tashani, Tabasam \& Johnson, 2012; Reidy, Dimmick, MacDonald \& Zeichner, 2009). Multi-centered randomized experimental and prospective studies are warranted to confirm these preliminary findings and to further examine the relationship between the key variables examined.

Our findings are preliminary and need to be interpreted with caution because of the crosssectional nature of the study design employed. Furthermore, the results obtained were based on a non-random sample and limited to one university setting only. By convention, VDT use is divided into 3 categories: high-end, medium or low-end users. In our study, no participant reported being exposed to VDTs $<5 \mathrm{hrs}$. /day. In other words, all participants were high-end users. Implications of these findings may include interventions geared at prevention such as ergonomic designs for desks in university classrooms, effectiveness of range of motion. Particular attention needs to be directed to investigating negative health effects associated with the use/abuse of VDTs. Moreover, it is important that young adults learn these negative health effects associated with VDTs given the fact that even younger adults are currently frequent users of technologies. Furthermore, limiting exposure to VDT-based devices through frequent breaks, 
look away icon/apps for laptops, cellular phones maybe helpful in reducing negative health effects associated with VDT use (Balci \& Aghazadeh, 2003). 


\section{References}

Alabus, O., Tashani, O., Tabasam, G., Johnson, M. (2012). Gender role affects experimental pain responses: A systematic review with meta-analysis. European Journal of Pain, 16(9), 1211-1223. doi:10.1002/j.1532-2149.2012.00121.x

Balci, R. and Aghazadeh, F. (2003). The effect of work-rest schedules and type of task on the discomfort and performance of VDT users. Ergonomics, 46(5), 455-465.

Bartley, E., Fillingham, R. (2013). Sex differences in pain: A brief review of clinical and experimental findings. British Journal of Anaesthesia 111(1), 52-58. doi: $10.1093 / \mathrm{bja} / \mathrm{aet} 127$

Berkley, K. (1997) Sex differences in pain. Behavioral and Brain Sciences, 20(3), 371-380.

Burns, N., Grove, S. (2011). Clarifying measurement and data collection in quantitative research. In N. Burns and S.K. Grove ( $5^{\text {th }}$ ed.), Understanding nursing research: Building an evidence-based practice (pp. 360-361). Maryland Heights, MO: Elsevier Saunders

CEFRIO. (2010). L'explosion des medias sociaux au Québec. Netendance 2010, 1.4. QC. http://www.cefrio.qc.ca/media/uploader/medias_sociaux.pdf

Cook, T., Roserance, J., Ketchen, K., Merlino, L., Anton, D. (2002). Test-retest reliability of a self-administered musculoskeletal symptoms and job factors questionnaire used in ergonomics research. Applied Occupational and Environmental Hygiene, 17(9), 613-621.

Crawford, J. (2007). The Nordic Musculoskeletal Questionnaire. Occupational Medicine, 57(4), 300-301. 
Darnall, B., Suarez, E. (2009). Sex and gender in psychoneuroimmunology research: Past, present and future. Brain, Behaviour and Immunity, 23(5), 595-604. doi: 10.1016/j.bbi.2009.02.019

Das, B., and Ghosh, T. (2010). Assessment of ergonomical and occupational health related problems among VDT workers of West Bengal, India. Asian Journal of Medical Sciences $1(2), 26-31$.

El-Bestar, S.F., El-Mitwalli, A.A., Kashaba, E.O. (2011). Neck-upper extremity musculoskeletal disorders among workers in the telecommunications company at Mansoura City. International Journal of Occupational Safety and Ergonomics, 17(2)195-205.

Gerritsen, A., Deville, W. (2009). Gender differences in health and health care utilisation in various ethnic groups in the Netherlands: A cross-sectional study. Biomedcentral Public Health, 9(109), 1-7. doi: 10.1186/1471-2458-9-109

Greenspan, J., Craft, R., LeReche, L., Aredt-Nielsen, L., Berkley, K., Fillingim, R., ...Traub, R. (2007). Studying sex and gender differences in pain and analgesia: A consensus report. Pain, 132(Supplement 1), S26-S45. doi: 10.1016/j.pain.2007.10.014

Hakala, P.T., Saarni, L.A., Ketola, R.L. Rahkola, E.T., Salminen, J.J., Rimpela, A.H. (2010). Computer-associated health complaints and sources of ergonomic instructions in computerrelated issues among Finnish adolescents: a cross-sectional study. Biomedcentral Public Health, 10(11), 1-8.

Ho, R. (2014). Multiple regression. In Robert Ho ( $2^{\text {nd }}$ ed.), Handbook of Univariate and Multivariate data analysis with IBM SPSS (pp. 283-334). Boca Raton, FL: CRC Press 
Hsu, W., Wang, M. (2003). Physical discomfort among visual display terminal users in a semiconductor manufacturing company: A study of prevalence and relation to psychological and physical/ergonomic factors. American Industrial Hygiene Association (AIHA), 64(2)276.-282.

Huber, M., Knottnerus, J., Green, L., Horst, H., Jadad, A., Kromhout, D... Smid, H. (2011). How should we define health? British Medical Journal, 343(D4163), 1-3. doi:10.1136/bmj.d4163

Internet World Stats. (2014). Mobile Internet-Mobile phones and smart mobile phones. Retrieved from http://www.Internetworldstats.com/mobile.htm

Johnston, V., Jull, G., \& Jimmieson, N. (2010). Interactive effects from self-reported physical and psychosocial factors in the workplace on neck pain and disability in female office workers. Ergonomics, 53(4), 502-513. doi: 10.1080/0014030903490692

Klussman, A., Gebhardt, H., Liebers, F. and Rieger, M.A. (2008). Musculoskeletal symptoms of the upper extremities and the neck: A cross-sectional study on prevalence and symptompredicting factors at visual display terminal (VDT) workstations. Biomedcentral Musculoskeletal Disorders, 9(96), 1-16.

Kormas, G., Critselis, E., Janikian, M., Kafetzis, D., Tsitsika, A. (2011). Risk factors and psychosocial characteristics of potential problematic and problematic Internet use among adolescents: A cross-sectional study. Biomedcentral Public Health, 11:595. doi: $10.1186 / 1471-2458-11-595$

Kuorinka, I., Jonsson, B., Kilborn, A., Vinterberg, H., Biering-Sorensen, F., Anderson, G., Jorgensen, K. (1987). Standardized Nordic questionnaires for the analysis of musculoskeletal symptoms. Applied Ergonomics, 18(3), 233-237. 
Lenior, M., Dingemans, P., Schene, A., Linszen, D. (2005). Predictors of the early 5-year course of schizophrenia: A path analysis. Schizophrenia Bulletin, 31(3), 781-791. doi: $10.1093 / \mathrm{schbul} / \mathrm{sbi010}$

Loghmani, A., Golshiri, P., Zamani, A., \& Kheirmand, M. (2013). Musculoskeletal symptoms and job satisfaction among office-workers: A cross-sectional study from Iran. Acta Medica Academica, 42(1), 46-54. doi:10.5644/ama2006-124.70

O’Neill, M., Simard, P., Sasseville, N., Mucha, J., Losier, B., Niquette, M. (2012). “Promoting health through the setting approach". In Health Promotion in Canada-Critical Perspectives on practice, I. Rootman, S. Dupéré, A. Pederson, \& M. O’Neill (Eds) (pp. 171-192). Toronto, ON: Canadian Scholar's Press International

Pillastrini, P., Mugnai, R., Bertozzi, L., Costi, S., Curti, S., Guccione, A., Mattioli, S., Violante, F. (2010). Effectiveness of an ergonomic intervention on work-related posture and low back pain in video display terminal operators: A 3 year cross-over trial. Applied Ergonomics, 41(3), 436-443

Polit, D., Hungler, B. (1991). Advanced statistical procedures. In Denise Polit \& Bernadette Hungler ( $4^{\text {th }}$ ed.), Nursing Research: Principles and Methods (pp. 480-482). Philadelphia, PA: Lippincott Company.

Rajagopal, V., R.M. Rosli, P. Rintai, N. Rustim and R. Benadus (2012). The prevalence of computer-related musculoskeletal pain among college students-a cross-sectional study. American Medical Journal, 3, 33-36.

Raynes, E. P. (2001). Nematic Liquid Crystals: Applications. In K. H. Jürgen Buschow, Robert W. Cahn, Merton C. Flemings, Bernard Ilschner (print), Edward J. Kramer, Subhash 
Mahajan, and Patrick Veyssière ( $2^{\text {nd }}$ Ed). Encyclopedia of Materials: Science and Technology. pp. 6059-6065. Oxford, UK. Elsevier.

Reidy, D., Dimmick, K., MacDonald, K. Zeichner, A. (2009). The relationship between pain tolerance and trait aggression: Effects of sex and gender roles. Aggressive Behaviour, 35(5), 422-429. doi: 10.1002/ab.20315.

Smith, L., Louw, Q., Crous, L., Grimmer-Somers, K. (2009). Prevalence of neck pain and headache: Impact of computer use and other associative factors. Cephalgia, 29(2), 250257. doi: 10.1111/ j.1468-2982.2008.01714.x

Spallek, M., Kuhn, W., Uibel, S, van Mark, D, Quarcoo (2010). Work-related muscle disorders in the automotive industry due to repetitions of work-implications for rehabilitation. Journal of Occupational Medicine and Toxicology, 5(6), 1-6.

Statistics Canada (2013). Women and university programs. Statistics Canada. Retrieved on February 5, 2015 from the Government of Canada website http://www.statcan.gc.ca/pub/89-503-x/2010001/article/11542-eng.htm\#a10

Travers, P.H., Stanton, B. (2002). Office workers and video display terminals: Physical, psychological and ergonomic factors. Association of American Occupational Health Nurses Journal, 50(11)489-493.

Wang, Y., Hunt, K., Nazareth, I., Freemantle, N., \& Petersen, I. (2013). Do men consult less than women? An analysis of routinely collected UK general practice data. British Medical Journal Open, 3(8:e003320), 1-8. doi: 10.1136/bmjopen-2013-003320 
Waterman, L., \& Weinman, J. (2014). Medical student syndrome: Fact or fiction? A crosssectional study. Journal of the Royal Society of Medicine, 5(2), 1-9. doi: $10.1177 / 204253331352480$

World Health Organization. (2010). Interphone study on mobile phone use and brain cancer risk. http://www.iarc.fr/en/media-centre/pr/2010/pdfs/pr200_E.pdf

Wu, S., He, L., Li, J., Wang, J., \& Wang, S. (2012). Visual Display Terminal use increases the prevalence and risk of work-related musculoskeletal disorders among Chinese office workers: A Cross-sectional Study. Journal of Occupational Health, 54(1), 34-43.

Young, S. A. (1990). The health effects of video display terminals. Professional Safety, 35(11), $40-43$. 